\title{
Estimating adolescent sleep patterns: parent reports versus adolescent self-report surveys, sleep diaries, and actigraphy
}

This article was published in the following Dove Press journal:

Nature and Science of Sleep

II February 2013

Number of times this article has been viewed

\author{
Michelle A Short ${ }^{1,2}$ \\ Michael Gradisar' \\ Leon C Lack' \\ Helen R Wright' \\ Alex Chatburn²
}

'School of Psychology, Flinders University, ${ }^{2}$ Centre for Sleep Research, University of South Australia, Adelaide, South Australia, Australia
Correspondence: Michelle A Short Centre for Sleep Research, University of South Australia, GPO Box 2100, Adelaide SA 500I, Australia Tel $+6 \mid 883021966$

Fax +61883026623

Email michelle.short@unisa.edu.au
Background: In research and clinical contexts, parent reports are often used to gain information about the sleep patterns of their adolescents; however, the degree of concordance between parent reports and adolescent-derived measures is unclear. The present study compares parent estimates of adolescent sleep patterns with adolescent self-reports from surveys and sleep diaries, together with actigraphy.

Methods: A total of 308 adolescents (59\% male) aged 13-17 years completed a school sleep habits survey during class time at school, followed by a 7-day sleep diary and wrist actigraphy. Parents completed the Sleep, Medical, Education and Family History Survey.

Results: Parents reported an idealized version of their adolescent's sleep, estimating significantly earlier bedtimes on both school nights and weekends, significantly later wake times on weekends, and significantly more sleep than either the adolescent self-reported survey, sleep diary, or actigraphic estimates.

Conclusion: Parent reports indicate that the adolescent averages a near-optimal amount of sleep on school nights and a more than optimal amount of sleep on weekends. However, adolescent-derived averages indicate patterns of greater sleep restriction. These results illustrate the importance of using adolescent-derived estimates of sleep patterns in this age group and the importance of sleep education for both adolescents and their parents.

Keywords: concordance, parent, sleep, sleep measurement, survey, actigraphy

\section{Introduction}

Adolescent sleep patterns are measured in different ways. Many studies have relied upon survey data to estimate adolescent sleep patterns, either using parent report, ${ }^{1-6}$ adolescent self-report surveys, or sleep diaries, ${ }^{7}$ but fewer have utilized actigraphic estimates of sleep. ${ }^{8}$ There is some uncertainty around the differences in results obtained by these different methods, ${ }^{7,9}$ and around parent reporting in particular. ${ }^{10}$ One study found that parents of children aged 3-10 years overestimated their child's sleep by an average of one hour and 53 minutes per night, compared with concurrently recorded actigraphic estimates. ${ }^{10}$ Parents may be susceptible to socially desirable responding when estimating the sleep patterns of their child. ${ }^{11}$ Further, parent reports of their adolescent's sleep may align more closely with the time that adolescents spend in their bedroom at night, because parents are not aware of the length of time spent awake after lights out. Given the many biopsychosocial factors which predispose adolescents to later sleep-onset times (such as circadian phase delay, changes in accumulation of homeostatic sleep pressure, and increased academic and social responsibilities), plus the propensity for adolescents to access computers, mobile phones, and music players 
after bedtime, parents may not be in a position to provide accurate estimates of sleep. ${ }^{12,13}$ An exception to this may be wake times, as parents of adolescents become less involved in regulating bedtimes but more involved in waking them in the morning. ${ }^{13}$

This is a concern that has substantial ramifications in both clinical and research settings. If parents are not able to describe their adolescent's sleep patterns accurately, it calls into question previous research which has used this methodology. In addition, if parents do not have an accurate estimation of their teen's sleep, especially if they overestimate their sleep, they may not be aware of problematic levels of restricted sleep and so may not provide the support required to address this. To address this concern, the present study compared adolescent survey, sleep diary, and actigraphic estimates of sleep and time in bed with parent-reported sleep. Consistent with the findings of Dayyat et a ${ }^{10}$ among children aged 3-10 years, it is hypothesized that parent reports will significantly overestimate sleep duration compared with adolescent-derived estimates and actigraphy. It is also hypothesized that parents will significantly underestimate the lateness of adolescent bedtimes, but there will be no significant difference between parent and adolescent reports of wake times. The present study extends the previous work by including adolescent-reported survey and sleep diary data in addition to actigraphy.

\section{Materials and methods}

\section{Participants}

In total, 308 adolescents of mean age 15.6 \pm 0.94 (range 13-17) years $(59 \%$ male) with a parent or caregiver $(77.2 \%$ mothers, $18.9 \%$ fathers, and $3.9 \%$ another family members/caregivers) participated in this study. Participants were drawn from eight high schools in South Australia and were in years 9, 10, and 11. Mean school start time was 8:32 am (standard deviation 0.28 hours). The study had no exclusion criteria, and adolescents were reimbursed for their time with a $\$ 40$ gift voucher. The Flinders University Social and Behavioral Research Ethics Committee and the Department of Education and Children's Service approved this study.

\section{Measures}

Adolescents completed a modified Sleep Habits Survey ${ }^{14}$ during class time at school. This survey contained items relating to bedtime, wake time, and total sleep time for both school nights and weekends. For the following week, they completed a sleep diary morning and night, which asked adolescents to record their daily bedtime, wake time, and sleep duration. Adolescents were asked to fill out the sleep diary just before they went to bed each night and as soon as they woke in the morning. Adolescents indicated exact times for all sleep variables.

In order to provide an objective measure of sleep, adolescents wore MicroMini Motionlogger activity monitors (Ambulatory Monitoring, Ardsley, NY, USA) on the nondominant wrist. Data were digitized in one-minute epochs using zero crossing mode, with a sensitivity of $0.05 \mathrm{~g}$, and analyzed with Action W2 software using the Sadeh algorithm. Diary data were used to define the scoring interval for sleep according to the procedure outlined by Acebo et al. ${ }^{15}$ While sleep onset is a biological state change that can be inferred from actigraphic movement data, bedtime is a behavioral phenomenon that cannot be captured by analysis of movement. Unfortunately, the activity monitors used were not equipped with an event marker function to capture bedtime. As such, data regarding bedtime were collected from self-reported and parent-reported surveys and sleep diaries only.

Parents completed the Sleep, Medical, Education and Family History Survey developed by Carskadon et al at the Sleep for Science research laboratory at Brown University (Carskadon, unpublished data, 1999). In addition to demographic items, this tool contains questions about the time when the adolescent went to bed and woke up on school (Sunday to Thursday) nights and weekends (Friday and Saturday nights).

\section{Results}

One-way repeated-measures analyses of variance with post hoc comparisons were utilized to compare average values of sleep parameters according to measurement mode, using the Statistical Program for the Social Sciences version 20 (SPSS Inc, Chicago, IL, USA). Analyses of variance were conducted separately for school nights and weekend nights for each sleep parameter. Table 1 shows mean values for sleep variables according to measurement mode (either actigraphy, sleep diary, self-report survey, or parent report), together with mean differences between parent reports and each measure and the significance of any differences observed. Bonferroni adjustments were made to allow for multiple comparisons.

The results of this study demonstrate significant and substantial differences between the averages estimated by actigraphy, sleep diary, and self-report of the adolescents and those reported by parents. Parents reported that their adolescents went to bed 14-18 minutes earlier and obtained 35-45 minutes more sleep on school nights compared with adolescent-derived estimates. On weekends, parents reported that their adolescents went to bed 18-35 minutes earlier, 
Table I Mean values for sleep parameters from parent report compared to wrist actigraphy, sleep diary, and self-report survey, together with mean ( \pm se) differences

\begin{tabular}{|c|c|c|c|c|c|c|c|c|c|c|}
\hline \multirow[t]{2}{*}{ Variable } & \multirow{2}{*}{$\frac{\text { Parent }}{X}$} & \multicolumn{3}{|c|}{ Actigraphy } & \multicolumn{3}{|l|}{ Diary } & \multicolumn{3}{|l|}{ Survey } \\
\hline & & $x$ & Diff ( \pm se $)$ & $P^{*}$ & $x$ & Diff ( \pm se $)$ & $P^{*}$ & $x$ & Diff ( \pm se $)$ & $P^{*}$ \\
\hline \multicolumn{11}{|l|}{ School night } \\
\hline Sleep period & $8 \mathrm{~h} 51 \mathrm{~m}$ & 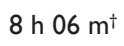 & $45 \mathrm{~m}(2.92)$ & $<0.001$ & $8 \mathrm{~h} 16 \mathrm{~m}$ & $35 \mathrm{~m} \mathrm{(3.13)}$ & $<0.001$ & $8 \mathrm{~h} 10 \mathrm{~m}$ & $41 \mathrm{~m}(4.26)$ & $<0.001$ \\
\hline Bedtime & 10:09 pm & - & - & - & $10: 28 \mathrm{pm}$ & $-18 \mathrm{~m}(0.04)$ & $<0.00 \mathrm{I}$ & $10: 24 \mathrm{pm}$ & $-14 \mathrm{~m}(0.04)$ & $<0.00$ I \\
\hline Wake time & $6: 57 \mathrm{am}$ & 7:03 am & $-6 \mathrm{~m}(0.04)$ & ns & 7:07 am & $-10 \mathrm{~m}(0.03)$ & $<0.001$ & $6: 54 \mathrm{am}$ & $-3 \mathrm{~m}(0.02)$ & ns \\
\hline \multicolumn{11}{|l|}{ Weekends } \\
\hline Sleep period & $10 \mathrm{hol} \mathrm{m}$ & $8 \mathrm{~h} 29 \mathrm{~m}^{\dagger}$ & I h 32 m (6.17) & $<0.001$ & $8 \mathrm{~h} 41 \mathrm{~m}$ & I h $21 \mathrm{~m}(6.09)$ & $<0.001$ & $9 \mathrm{~h} 21 \mathrm{~m}$ & $40 \mathrm{~m}(6.72)$ & $<0.001$ \\
\hline Bedtime & I I:20 pm & - & - & - & I I:38 pm & $-18 \mathrm{~m}(0.07)$ & $<0.001$ & II:54 am & $-35 \mathrm{~m}(0.07)$ & $<0.001$ \\
\hline Wake time & $9: 16$ am & $8: 26$ am & $51 \mathrm{~m}(0.09)$ & $<0.001$ & $8: 30 \mathrm{am}$ & $47 \mathrm{~m}(0.08)$ & $<0.001$ & $9: 22$ am & $6 \mathrm{~m}(0.08)$ & ns \\
\hline
\end{tabular}

Notes: ${ }^{\dagger}$ Actigraphic sleep period was calculated as the time elapsed from sleep onset to sleep offset; *bonferroni adjustment used to adjust for multiple comparisons.

and obtained 40-92 minutes more sleep per night than adolescent-derived estimates. Parent wake time estimates on school days were more similar to the reports derived from their adolescents, with only sleep diary estimates being a significant, but small, 10 minutes later than the parent report. Unlike wake times on school mornings, parent estimates of weekend sleep were more divergent, with parents estimating wake times occurring 47-51 minutes later than adolescent sleep diary and actigraphic estimates. The survey reported that weekend wake times were not significantly different from parent reports.

\section{Discussion}

\section{How should we measure adolescent sleep?}

To the authors' knowledge, this is the first study to compare parent reports of adolescent sleep with adolescent self-report, sleep diary self-report, and actigraphy in typically developing adolescents. When comparing the different ways of collecting data on adolescent sleep, significant differences in results were obtained depending on the method used. Parents reported a much more idealized sleep pattern, estimating that their adolescent went to bed earlier and obtained more sleep on both school nights and on weekends than did the adolescent. These results are consistent with those found in younger children. ${ }^{10}$ While there were some significant differences in school morning wake time estimates between parent reports and actigraphic and sleep diary estimates, these differences were small. Parents may be more accurate in estimating their teens' school morning wake times compared with bedtimes because of the diminished parental involvement in regulating adolescent bedtimes and increased involvement in waking teens for school with increasing age. On weekends, the difference between parent reports and sleep diary and actigraphy was greater for wake time, with parents overestimating wake times by $48-50$ minutes. This finding is unexpected, and inconsistent with previous findings. ${ }^{10} \mathrm{It}$ may be that parents are less involved in adolescent wake times on weekends when compared with school mornings, and so are not able to provide accurate wake time estimates. ${ }^{16}$ In addition, adolescents are more likely to maintain quiet wakefulness in the morning without disturbing their parent/s than are younger children.

The differences between parent and adolescent and actigraphic estimates of sleep are important, and show that adolescent sleep is likely to be much more restricted than their parents believe. In fact, parent reports reveal that they believe their teens are obtaining a near-optimal amount of sleep. ${ }^{8}$ This is significant on two levels. The first important implication of these findings regards the utility of parent reports for sleep research. Previous studies that have utilized parent reports to estimate sleep are called into question. At the very least, it is likely that these reports overestimate sleep and underestimate bedtimes. The present study provides support for the use of adolescent reports in preference to parent reports of teen sleep. Secondly, it highlights the importance of educating parents about teen sleep. It may be that because teens are less visible than younger children after they go to bed, parents assume that they are asleep, when in fact they are likely to be awake. Particularly with the presence of a wide array of electronic media in the bedroom and the biological propensity toward phase delay and wakefulness in the evening, teens may quietly maintain wakefulness well into the night without parental awareness. ${ }^{17,18}$ Parents can have an important role in regulating the sleep patterns of adolescents, with associated improvements in daytime functioning, but are unlikely to act if they are not aware that their teens is not obtaining sufficient sleep. ${ }^{19}$

A strength of this study is the range of sleep measures obtained, in particular sleep diary and actigraphy, in a 
relatively large sample of adolescents and parents. The present study highlights the importance of relying upon adolescent-derived estimates to obtain data on sleep patterns in this age group. In addition, parent education is indicated to enable parents to have a more accurate picture of their adolescents' sleep.

\section{Acknowledgment}

This work was conducted at the Flinders University of South Australia and was funded by the Australian Research Council (grant DP0881261).

\section{Disclosure}

The authors declare no conflicts of interest in this work.

\section{References}

1. Iglowstein I, Jenni OG, Molinari L, Largo RH. Sleep duration from infancy to adolescence: reference values and generational trends. Pediatrics. 2003;111:302-307.

2. Gangwisch JE, Babiss LA, Malaspina D, Turner JB, Zammit GK, Posner K. Earlier parental set bedtimes as a protective factor against depression and suicidal ideation. Sleep. 2010;33:97-106.

3. Smaldone A, Honig JC, Byrne MW. Sleepless in America: inadequate sleep and relationships to health and wellbeing of our nations' children. Pediatrics. 2007;119:529-537.

4. Gregory AM, Van der Ende J, Willis TA, Verhulst FC. Parent-reported sleep problems during development and self-reported anxiety/depression, attention problems, and aggressive behavior later in life. Arch Pediatr Adolesc Med. 2008;162:330-335.

5. Pirinen T, Kolho KL, Simola P, Ashorn M, Aronen ET. Parent and selfreport of sleep problems and daytime tiredness among adolescents with inflammatory bowel disease and their population based controls. Sleep. 2010;33:1487-1495.
6. Laberge L, Petit D, Simard C, Vitaro F, Tremblay RE, Montplasir J. Development of sleep patterns in early adolescence. J Sleep Res. 2001;10:59-67.

7. Wolfson AR, Carskadon MA, Acebo C, et al. Evidence for the validity of a sleep habits survey for adolescents. Sleep. 2003;26:213-216.

8. Gradisar M, Gardner G, Dohnt H. Recent worldwide sleep patterns and problems during adolescence: a review and meta-analysis of age, region, and sleep. Sleep Med. 2010;12:110-118.

9. Short MA, Gradisar M, Lack L, Wright H, Carskadon MA. The discrepancy between actigraphic and sleep diary measures of sleep in adolescents. Sleep Med. 2012;13:378-384.

10. Dayyat EA, Spruyt K, Molfese DL, Gozal D. Sleep estimates in children: parental versus actigraphic assessments. Nat Sci Sleep. 2011;3:115-123.

11. Pauls CA, Stemmler G. Substance and bias in social desirability responding. Pers Individ Dif. 2003;35:263-275.

12. Jenni OG, Achermann P, Carskadon MA. Homeostatic sleep regulation in adolescents. Sleep. 2005;28:1446-1454.

13. National Sleep Foundation. Sleep in America Poll 2006. Washington, DC. Available from: http://www.sleepfoundation.org/article/sleepamerica-polls/2006-teens-and-sleep. Accessed November 16, 2012.

14. Wolfson AR, Carskadon MA. Sleep schedules and daytime functioning in adolescents. Child Dev. 1998;69:875-887.

15. Acebo C, Sadeh A, Seifer R, et al. Estimating sleep patterns with activity monitoring in children and adolescents: how many nights are necessary for reliable measures? Sleep. 1999;22:95-103.

16. Short MA, Gradisar M, Lack LC, Wright HR, Dohnt H. The sleep patterns and well-being of Australian adolescents. J Adolesc. October 19, 2012. [Epub ahead of print.]

17. Cain N, Gradisar M. Electronic media use and sleep in school-age children and adolescents: a review. Sleep Med. 2010;11:735-742.

18. Taylor DJ, Jenni OG, Acebo C, Carskadon MA. Sleep tendency during extended wakefulness: insights into adolescent sleep regulation and behavior. J Sleep Res. 2005;14:239-244.

19. Short MA, Gradisar M, Wright H, Lack LC, Dohnt H, Carskadon MA. Time for bed: parent-set bedtimes associated with improved sleep and daytime functioning in adolescents. Sleep. 2011;34:797-800.
Nature and Science of Sleep

\section{Publish your work in this journal}

Nature and Science of Sleep is an international, peer-reviewed, open access journal covering all aspects of sleep science and sleep medicine, including the neurophysiology and functions of sleep, the genetics of sleep, sleep and society, biological rhythms, dreaming, sleep disorders and therapy, and strategies to optimize healthy sleep. The journal welcomes

\section{Dovepress}

original research, clinical \& epidemiological studies, reviews \& evaluations, case reports and extended reports. The manuscript management system is completely online and includes a very quick and fair peerreview system, which is all easy to use. Visit http://www.dovepress.com/ testimonials.php to read real quotes from published authors. 